\title{
Trabalho ou benefício de prestação continuada: a escolha da família do jovem com Síndrome de Down
}

\author{
Employement or government benefit: the choice of the family for youngsters with Down \\ syndrome
}

\author{
Ana Lívia Urbini Rocha* \\ Maria de Fatima Campos Françozo**
}

\begin{abstract}
Resumo:
O Benefício de Prestação Continuada (BPC) é uma política de proteção social destinada à pessoa com deficiência e ao idoso em condição de vulnerabilidade. O objetivo deste estudo foi conhecer o significado que a família atribui ao BPC e ao trabalho, bem como, as escolhas feitas para o jovem com Síndrome de Down (SD). Trata-se de um estudo qualitativo, em que foram entrevistados 11 pais ou responsáveis por jovens com SD, que recebem ou já receberam o BPC e que tiveram alguma experiência de trabalho. A maioria dos participantes é beneficiário do BPC há mais de 10 anos. Para muitos o benefício está incorporado ao orçamento familiar e é fundamental para o sustento da casa. Este é um dos motivos pelos quais muitos dos jovens não trabalham. Outras razões referem-se às dificuldades dos pais em levá-los ao trabalho e a percepção de que o local não é seguro para eles. A escolha entre o benefício ou o trabalho é feita pela família. Experiências positivas daqueles que trabalham são referidas como a autonomia e independência. Há necessidade de políticas sociais de orientação às famílias em relação aos direitos ao benefício e ao papel que o trabalho tem para o jovem com SD.
\end{abstract}

Palavras-Chave: Benefício de prestação continuada. Síndrome de down. Emprego. Relações familiares.

\begin{abstract}
:
The Continued Cash Benefit CCB is a social protection policy to the disabled and the elderly. It is an unconditional transfer of income, equivalent to a minimum wage for people with disabilities living on vulnerable conditions. This study aimed to discuss the meaning that parents or guardians of Youngers with down syndrome (DS) assign to the benefit, to employment, and how they choose among them one or another. This was a qualitative study that interviewed 11 parents or guardians of youngsters with down syndrome who receive or have received the CCB and who had some work experience. The participants have received the benefit for up to 10 years. For many, the benefit is added to assimilated as a source of family income to be spent on domestic needs. This is one of the reasons for youngsters not to work. Other reasons are related to family difficulties to accompany him to work and feelings that he is not protected in the workplace. The positive experiences of those who work are autonomy and independence. Families choose whether the youngster works or keeps the benefit. Social policies are necessary to improve family knowledge about their rights concerning the CCB and about the role of working on the youngster's life.
\end{abstract}

Keywords: Continued cash benefit. Down syndrome. Employment. Family relation.

\footnotetext{
* Mestre em Saúde, Interdisciplinaridade e Reabilitação pela Universidade Estadual de Campinas.

** Doutora em Saúde Mental pela Universidade Estadual de Campinas. Docente em Educação Especial e Reabilitação junto ao departamento de Desenvolvimento Humano e Reabilitação e ao Centro de Estudos e Pesquisas em Reabilitação "Prof. Dr. Gabriel Porto", da Faculdade de Ciências Médicas da Universidade Estadual de Campinas.
} 


\section{Introdução}

Nos últimos anos, houve uma evolução na concepção de deficiência e dos direitos sociais relacionados às pessoas com deficiência. Por muitos anos vigorou uma concepção de deficiência influenciada por um modelo médico que relacionava a deficiência a uma condição orgânica de natureza incapacitante (KASSAR, 2000).

O modelo médico da deficiência influenciou a sociedade de tal forma que, ainda hoje, é muito comum encontrar quem considere a pessoa com deficiência como doente (SASSAKI, 1997).

No século XXI, a Organização Mundial de Saúde (OMS), passou a considerar a deficiência como uma questão não apenas biomédica, mas de direitos humanos. Nesse momento, a Classificação Internacional de Doenças CID -10 começou a ser revista, para dar espaço à Classificação Internacional de Funcionalidade, Incapacidade e Saúde - CIF. A primeira faz uma classificação de corpos anormais, enquanto a CIF faz uma avaliação complexa da relação entre o indivíduo e a sociedade (DINIZ; BARBOSA; SANTOS, 2009).

O declínio da concepção biomédica possibilitou a transição para o "modelo social" no qual a sociedade deve assumir responsabilidade pela deficiência. Explicar que a situação de opressão sofrida pelos deficientes é devida às perdas de habilidades, provocadas pela lesão, é confundir lesão com deficiência. Para os estudiosos, deficiência é fenômeno sociológico e lesão é expressão biológica (BAMPI; GUILHEM; ALVES, 2010; p. 6).

O modelo social da deficiência, ao resistir à redução da deficiência aos impedimentos, ofereceu novos instrumentos para a transformação social e a garantia de direitos. A deficiência passou a ser compreendida como uma experiência de desigualdade compartilhada por pessoas com diferentes tipos de impedimentos, que são discriminadas pela sociedade (DINIZ; BARBOSA; SANTOS, 2009).

Neste modelo, a deficiência não se resume às alterações corporais porque as pessoas experimentam restrições significativas também por força das barreiras ambientais e econômicas. Frente a nova concepção, a politica pública tem sido pressionada para prover acessibilidade, vida independente e oportunidades de emprego e renda para a pessoa com deficiência (COSTA et al., 2016).

O modelo social retira o foco do indivíduo e da doença, sendo a deficiência vista como produção social, que demanda respostas sociais e políticas públicas adequadas (SENNA; LOBATO, 2013). 
Sem recusar a atenção médica e de reabilitação, o modelo social da deficiência apontou as insuficiências do modelo médico e expôs a necessidade de estabelecimento de políticas públicas para os deficientes como uma questão de justiça social e de defesa dos direitos humanos (SENNA; LOBATO, 2013).

Dentre os tipos de deficiência, encontra-se a deficiência intelectual. Sua história é semelhante à de todos os tipos de deficiências no sentido do movimento inicial de busca por direitos.

Os diferentes aspectos da deficiência intelectual constituem um desafio tanto para os profissionais envolvidos na sua investigação diagnóstica e cuidados, bem como para o indivíduo com deficiência e seus familiares. A redução da capacidade intelectual pode ser indicada por diferentes formas. Os termos mais utilizados ao longo da história são retardo mental, deficiência mental e, o mais recente, deficiência intelectual.

A Deficiência Intelectual (DI) é resultado, quase sempre, de uma alteração no desempenho cerebral, provocada por fatores genéticos, distúrbios na gestação, problemas no parto ou na vida após o nascimento. Entre os inúmeros fatores que podem causar a deficiência intelectual, destacam-se alterações cromossômicas e gênicas, desordens do desenvolvimento embrionário ou outros distúrbios estruturais e funcionais que reduzem a capacidade do cérebro. No entanto, um dos desafios enfrentados pelos pesquisadores da área é que, em parte dos casos estudados, essa alteração não tem uma causa conhecida ou identificada.

Entre as diferentes deficiências intelectuais, está a síndrome de down (SD). As pessoas com SD têm seu desenvolvimento afetado pela alteração genética do cromossomo 21, provocando mudanças nas funções celulares desde a vida intrauterina. Essas mudanças implicam características que acompanharão o indivíduo em todo o seu processo evolutivo. A síndrome de down é a primeira causa conhecida de deficiência intelectual, representando aproximadamente $25 \%$ de todos os casos de atraso intelectual, traço presente em todas as pessoas que possuem a síndrome (RAUET, 2011).

Ao longo dos anos, as pessoas com deficiência foram conquistando muitos direitos, dentre eles, aqueles previstos na Constituição Brasileira de 1988. Esta representou um marco significativo dos avanços dos movimentos sociais, estabelecendo uma nova concepção de Seguridade Social como política pública, não contributiva, como direito de cidadania e dever do Estado (MARTINELLI, 2011).

No contexto das Políticas Públicas, em 1996, é instituído o Benefício de Prestação Continuada - BPC, benefício da assistência social, regulamentado pela Lei no 8742/93- Lei 
Orgânica da Assistência Social (LOAS). É uma transferência incondicional de renda, equivalente a um salário mínimo, destinado às pessoas com deficiência e ao idoso com 65 anos ou mais, que comprovem não possuir meios de prover a própria manutenção e nem tê-la provida por sua família, cuja renda per capita seja inferior a $1 \frac{1}{4}$ de salário mínimo. É um benefício individual, não vitalício, intransferível e que deve ser revisto a cada dois anos.

Atualmente, 4,2 milhões de pessoas recebem o BPC (BRASIL, 2017). O BPC buscagarantir à pessoa com deficiência uma maior autonomia, independência, a fim de assegurar e proteger socialmente a camada da população que enfrenta dificuldade para se inserir no mercado de trabalho.

Mas, mesmo quando o cidadão consegue o acesso ao benefício, ainda assim permanece com dificuldades, posto que o valor do benefício (um salário mínimo), acima se diz que é um quarto do mínimo, não consegue modificar significativamente a realidade das famílias que se encontram em precárias condições de vida. Segundo Netto (1999), são recursos mínimos destinados a pessoas incapazes de prover sua subsistência, cuja característica se torna pobre políticas sociais para os pobres.

Para Pereira (2002), é possível compreender que a focalização do benefício, uma vez que exige uma renda familiar per capita muito baixa, seleciona o mais pobre dentre todos os pobres. A pessoa com deficiência, em especial com SD, enfrenta diversas dificuldades ao longo da vida, dentre elas: a inclusão no mercado de trabalho. Ainda presente à concepção da deficiência como fator que incapacita a pessoa para o trabalho tem forte presença em nossa sociedade.

Na visão de Marx, o trabalho não é somente aquela atividade que promove a transformação da natureza, mas é uma atividade previamente idealizada que promove a transformação do próprio homem (COLMAN; POLA, 2009).

Explicam Lima, Silva, Galvão (2010) que o trabalho transforma a natureza, criando entre as pessoas as relações sociais que marcam o cotidiano. É um valor importante na vida de todos, com ou sem deficiência, e deve servir para enriquecer as pessoas e nunca como fonte de discriminação e sofrimento.

Para a pessoa com deficiência, o trabalho pode ter um sentido maior, pois ela sai da condição de isolamento social e da dependência de outros, para criar seus vínculos em outros espaços, com outras pessoas e desenvolvendo outras atividades (LIMA; TAVARES; BRITO, 2013). 
Para Lima, Silva e Galvão (2010), trabalhar é um dos melhores instrumentos que o ser humano dispõe para se realizar como pessoa, para manifestar operativamente necessidades e obrigação de servir os demais; mas, infelizmente encontram-se muitas barreiras para conseguir com que a pessoa com deficiência intelectual possa realizar-se com dignidade e inteireza em sua identidade como pessoa trabalhadora.

A concepção de trabalho foi se modificando no decorrer da história, e mais do que o objetivo primitivo de subsistência do homem, hoje, tem caráter social, como nos explica Giordano (2000, p. 50):

Seu significado, para os indivíduos, transcende a função de subsistência, para constituir-se num dos aspectos da identidade social. $O$ trabalho assume um lugar importante como atividade humana e como realidade social, devido a sua frequência e relevância na vida das pessoas.

Além de ser um meio de sobrevivência, o trabalho se constitui em uma forma de satisfação de necessidades sociais, de se relacionar com outras pessoas. Encontra-se,neste momento, a valorização da inserção e da relação social propiciada pelo trabalho. A integração social traz sentimentos de igualdade, que ajudam a quebrar o estereótipo social que rotula as pessoas como deficientes e incapazes (LIMA; TAVARES; BRITO, 2013).

O trabalho deve se constituir como fonte de satisfação na vida das pessoas, e não deveria ser diferente com as pessoas com deficiência. Entretanto, para que isso ocorra, deve haver,

[...] o resgate do papel do trabalho: seu potencial de elementos significativo, seja na autorrealização, seja na configuração da autoestima, seja na independência econômica, na autonomia, no prazer presente no processo e no produto, na sensação de aceitação e "pertencimento" (AMARAL, 1994, p.132).

A dimensão do trabalho como realidade social, como afirma Dejours (2004), é essencial à atividade humana, contribuindo para a satisfação de necessidades não apenas econômicas, mas também psicológicas e sociais. Por isso, a questão da inserção da pessoa com deficiência no mercado de trabalho tem sido alvo de políticas públicas que visam facilitar a entrada delas nas organizações.

Mas, a inserção do jovem com SD no mercado de trabalho gera dúvidas para a família, especialmente por que, com isso, ele deixa de receber o BPC - essa renda, muitas vezes, representa a segurança econômica da família. 
O objetivo deste trabalho foi conhecer o significado que a família atribui ao BPC e ao trabalho, bem como as escolhas feitas pela mesma para o jovem com SD.

\section{Método}

Tratou-se de um estudo de caráter qualitativo, pois este se preocupa com o universo de significados, motivos, aspirações, crenças, valores e atitudes inerentes aos atos, às relações e às estruturas sociais (MINAYO, 2004).

A amostra foi constituída por 11 pais ou responsáveis por jovens com diagnóstico de Síndrome de down, beneficiários do BPC, e/ou com alguma experiência de trabalho. O local da coleta de dados foi uma instituição que atende pessoas com Síndrome de down em suas diversas fases da vida, em um Município do interior do Estado de São Paulo. Os dados foram coletados no período de Setembro a Novembro de 2014.

A pesquisa foi realizada por meio de entrevista semiestruturada, guiada por um roteiro de questões que tratou sobre: BPC, tempo de recebimento do benefício, preparação do jovem para o mercado de trabalho, visão da família em relação à deficiência, ao benefício e ao trabalho.

As entrevistas foram gravadas com o consentimento dos participantes. O conteúdo das entrevistas foi transcrito por uma das pesquisadoras. Foram realizadas leituras sucessivas do conteúdo das entrevistas para posterior levantamento das categorias de análise, seguindose o modelo proposto por Bardin (2006), para análise de conteúdo.

O projeto de pesquisa teve a aprovação pelo Comitê de Ética em Pesquisa da Unicamp em 09/09/2014, parecer no 784.410, seguindo-se a Resolução 466/12.Na apresentação dos dados, os participantes foram identificados por números assim como os nomes de locais de trabalho são fictícios. Todos os participantes assinaram o termo de consentimento livre e esclarecido (TCLE).

\section{Resultados e Discussão}

Com o objetivo de caracterizar o perfil dos participantes da pesquisa e do familiar usuário do BPC, foram elaborados dois quadros, apresentados a seguir: 
Quadro 1 - Caracterização dos Participantes

\begin{tabular}{|c|c|c|c|c|c|c|}
\hline Participante & Parentesco & Idade & Escolaridade & Situação Trabalho & $\begin{array}{c}\text { No } \\
\text { Filhos }\end{array}$ & $\begin{array}{c}\text { Renda Familiar } \\
\text { (c/ BPC) }\end{array}$ \\
\hline P1 & Mãe & 62 & E.F.I & Aposentada & 02 & 2 SM \\
\hline P2 & Pai & 73 & E.F.I & Aposentado & 11 & 2 SM \\
\hline P3 & Avó & 64 & E.F.I & Do Lar & 06 & 3 SM \\
\hline P4 & Mãe & 68 & E.F.I & Do Lar & 10 & 1 SM \\
\hline P5 & Mãe & 52 & E.S.C & Desempregado & 01 & 3 SM \\
\hline P6 & Mãe & 42 & E.F.I & Empregadadoméstica & 02 & 2 SM \\
\hline P7 & Mãe & 53 & E.F.I & Diarista & 02 & 2 SM \\
\hline P8 & Mãe & 57 & E.F.I & Do Lar & 04 & 2 SM \\
\hline P9 & Mãe & 55 & E.F.I & Do Lar & 02 & 2 SM \\
\hline P10 & Mãe & 63 & E.F.I & Do Lar & 03 & 2 SM \\
\hline P11 & Mãe & 51 & E.F.I & Faz Bicos & 01 & 2 SM \\
\hline
\end{tabular}

*Legenda: E.F.I - Ensino Fundamental Incompleto; E.S.C - Ensino Superior Completo; E.F.C - Ensino Fundamental Completo; E.M.C - Ensino Médio Completo; SM - salário mínimo.

Fonte: Autor

Quadro 2 - Caracterização dos jovens: os títulos dos quadros estão em letra diferente, tabulação diferente etc.

\begin{tabular}{|c|c|c|c|c|}
\hline JOVEM & IDADE & ESCOLARIDADE & BPC & TEMPO DE BPC \\
\hline$J 1$ & 26 & E.F.I & Sim & Mais de 10 anos \\
\hline$J 2$ & 23 & E.F.I & Sim & 9 anos \\
\hline$J 3$ & 18 & E.F.I & Sim & Mais de 10 anos \\
\hline$J 4$ & 23 & E.M.C & Não & Trabalha \\
\hline$J 5$ & 25 & E.F.I & Sim & 7 anos \\
\hline$J 6$ & 18 & E.F.C & Não & Trabalha \\
\hline$J 7$ & 23 & E.F.I & Sim & Mais de 10 anos \\
\hline$J 8$ & 18 & E.F.C & Sim & Desde que nasceu \\
\hline$J 9$ & 30 & Não frequentou escola regular & Sim & Mais de 10 anos \\
\hline$J 10$ & 22 & E.F.C & Não & Trabalha \\
\hline$J 11$ & 18 & E.F.C & Sim & 10 anos \\
\hline
\end{tabular}

* O número de cada jovem (J), corresponde ao número de seu pai ou responsável (P) do quadro 1.

Fonte: Autor

Os dados apresentados nos quadros nos revelam o perfil dos jovens e suas famílias. Em relação ao perfil dos jovens, podemos observar que: 04 jovens concluíram o ensino fundamental e 01 concluiu o ensino médio. Aqueles que possuem maior grau de escolaridade estão inseridos no trabalho. Em relação ao BPC, apenas 03 jovens não estão recebendo o benefício atualmente, pois trabalham. O tempo de BPC daqueles que recebem é relativamente alto, alguns recebem há, aproximadamente, 10 anos; outros desde que nasceram, haja vista que já são jovens adultos. Isso nos revela que o BPC está incorporado à vida econômica da família. A renda familiar em geral não ultrapassa três salários mínimos (já incluso o BPC), o que significa que as famílias pertencem aos extratos pobres da população. 


\section{Visão da Família em Relação ao Trabalho}

Ao falar sobre o trabalho, os participantes revelaram um aspecto da visão que tem em relação ao jovem, a de que é alguém dependente.

Para Saad (2003) os pais de pessoas com deficiência mental, especialmente com SD, se esforçam para que seus filhos se desenvolvam e cresçam e quando isto acontece, sem perceber que já cresceram, continuam, em geral, tratando-os como se fossem crianças. Nesse contexto, tem dificuldades em aceitar a independência dos filhos.

A dependência aparece nas falas de participantes como a necessidade de cuidados especiais por parte do jovem com SD, necessidades estas que o impossibilitam de realizar um trabalho.

[...] têm umas crianças que são mais espertas que as outras, eu acho que tudo bem, mas tem uns que não tem condição de trabalhar, eu vejo assim.[...] Que nem uma criança que nem ela, ela pega muita amizade com as pessoas, se eu colocar ela pra trabalhar eu vou ter que ta lá no serviço, se eu tiver presente, ela não vai trabalhar, e eu ter que levar ela, deixar ela lá, eu não tenho condições, e deixar lá e voltar embora, eu não vou deixar ela sozinha, uma deficiente sozinha, vou ter que estar perto, não têm condições, entendeu? Pg-Mãe.

A visão de que o jovem é ainda uma criança indefesa, impossibilita pensar que possa ser independente, responsável por suas atitudes. Para Lepri (2012), a infantilização das pessoas com deficiência é totalmente coerente com uma organização social que, não prevendo papéis sociais ativos para elas, principalmente no mundo dos adultos, não pode planejar nem ao menos seu crescimento. A pessoa com deficiência torna-se:

[...] uma pessoa que nunca poderá crescer, amadurecer, passar pelas experiências típicas de uma pessoa adulta, por exemplo, aquelas ligadas à sexualidade ou à autonomia pessoal. Nessa situação, os familiares, em geral a mãe, são levados a proteger e cuidar da 'criança' durante todo o dia e por toda a vida, mesmo em situações nas quais ela poderia se virar sozinha (LEPRI, 2012, p. 105).

Para a maioria dos pais, o que os faz recuar quanto a favorecer à independência dos filhos é a ingenuidade dos mesmos em relação à periculosidade da cidade grande. Em sua maioria, eles reconhecem que seus filhos têm direito a ter planos e que gostariam de tornálos possíveis, mas não se sentem ancorados para 130decidir pela concretização da ideia, dentro de um caminho seguro (SAAD, 2003).

Nesse sentido, há outro participante que assim se expressa: 
Ela [nora] não quer que trabalhe, ela acha que a D. não tem mentalidade, por causa dela ser esquecida assim, que ela não tem possibilidade de trabalhar. P2 - Pai.

Outro ponto citado por alguns participantes como um obstáculo para o trabalho, é a questão da locomoção. Os pais ou responsáveis não deixam o jovem circular fora de casa sozinho, ele deve estar sempre acompanhado por alguém. Muitas vezes, os responsáveis não têm condições de acompanhá-los, dificultando o acesso do jovem aos serviços assim como ao lazer, à instituição, dentre outros.

Vai depender muito do tipo de trabalho pra ver se compensa, se vale a pena, porque dai tem aquele problema, tem que levar, tem que buscar, entendeu? Então tem que ver tudo isso. P7-Mãe.

Outra situação que chama atenção é que os pais frequentemente escolhem o tipo de emprego para o filho. Empregos com jornadas muito longas, sem folgas, finais de semana, em lugares muito populosos, não atraem a atenção dos pais. Para eles, em termos das condições de trabalho, não é qualquer situação que compensa para o filho e tudo é levado em consideração pela família no momento de decidir se o jovem irá trabalhar ou não.

Então...por ele num lugar pra trabalhar o dia inteiro, que nem num shopping, uma folga por semana, eu não vou colocar, entendeu? Porque eu acho que eles não têm necessidade disso. E eu não vou por, então, eu penso assim, vai depender muito do tipo de trabalho pra ver se compensa, se vale a pena. P7-Mãe.

Edwards (2009) explica que estamos nos distanciando do modelo tradicional nos quais as pessoas com deficiência tinham como única opção as oficinas abrigadas e que pessoas com SD podem se mostrar competentes numa variedade de serviços não abrigados, principalmente quando é possível que realizem escolhas baseadas em suas preferências individuais. Os serviços de apoio de emprego devem ajudar as pessoas com SD a explorar opções que forneçam salários e benefícios significativos.

Para Saad (2003), independentemente do retorno financeiro, o trabalho confere à pessoa valorização por parte de si mesmo e da sociedade, ao mesmo tempo em que desenvolve autonomia e independência. Esta independência para as pessoas com SD é relativa, porquanto sempre necessitarão de supervisão em algumas atividades que desempenham.

No Brasil, a Lei de Cotas (Lei 8. 213/91), em seu artigo 93, define que a empresa com 100 ou mais empregados, está obrigada a preencher de $2 \%$ a $5 \%$ dos seus cargos com beneficiários reabilitados ou pessoas com deficiência (BRASIL, 1991). Assim, muitas empresas 
passaram a executar as contratações sem nenhum tipo de planejamento, pois se não cumprissem a cota, seriam passíveis de multa. O papel da empresa, no entanto, não é apenas contratar, mas sim transformar e qualificar a pessoa com deficiência, além inserir-la, favorecendo sua manutenção no mercado de trabalho.

Pesquisas indicam que a maior parte dos trabalhadores com deficiência é alocada em funções específicas apenas para garantir o cumprimento da lei, o que pode sugerir falta de experiência dos gestores, falta de investimento na capacitação das pessoas com deficiência, descrença quanto à capacidade de liderar ou acomodação das próprias pessoas na função (TOLEDO; BLASCOVI-ASSIS, 2007).

Como a inclusão no trabalho não acontece, as pessoas acabam desenvolvendo o trabalho somente dentro dos muros da instituição.

A maioria dos programas de formação profissional voltados às pessoas com deficiência intelectual acontece dentro de instituições especializadas, que simulam um ambiente profissional, como, por exemplo, as oficinas protegidas, que é diferente de uma experiência verdadeira do mundo real do trabalho (LIMA; SILVA; GALVÃO, 2010).

Raiça, Prioste e Machado (2006) ressaltam que o ambiente profissional desempenha papel importante no ajustamento comportamental e social das pessoas com DI, tal como ocorre com qualquer outro indivíduo. Essa concepção de ambiente profissional se aproxima da noção do trabalho, para a pessoa deficiente, como forma de diminuição do isolamento social, o que contribui, além disso, para a melhoria de seu autoconceito e da própria vida.

Segundo Lima, Silva e Galvão (2010), é preciso sair dos modelos que implicam apenas a inclusão dessas pessoas como obrigação legal, por assistencialismo, mas reconhecer suas reais capacidades, competências, habilidades, como pessoa humana, em seu exercício de cidadania.

O direito ao trabalho é um direito de cidadania, perseguido como forma de integração social pela pessoa com deficiência, merecedora de iguais condições de oportunidades e reconhecimento como qualquer outra. A promoção dos direitos humanos das pessoas com deficiência é legitimada quando essa integração vem acompanhada de iguais condições de oportunidades e reconhecimento (LIMA; TAVARES; BRITO, 2013).

O trabalho para a pessoa com SD, amplia seu campo de autonomia pessoal, suas relações sociais, sua capacidade produtiva, bem como sua identidade enquanto pessoa.

De acordo com Machado e Chiari (2009), diversos fatores contribuem negativamente para o processo de inclusão da pessoa com deficiência intelectual no mercado de trabalho. 
Podemos citar os estigmas, tais como: a crença de que são incapazes, de que não conseguem maior independência e de que necessitam de constante supervisão. Um outro fator é a falta de preparo das empresas, de seus funcionários, e da própria pessoa com deficiência, no processo de adaptação ao emprego. Contudo, o trabalho não é um fim, mas um meio vital de cumprir sua função social. Entretanto, conseguir a inclusão da pessoa com SD no mercado formal é um grande desafio.

\title{
Experiência e/ou Desejo pelo Trabalho
}

Quando os participantes foram questionados se os jovens já haviam exercido alguma atividade laboral durante seu percurso pela instituição, pudemos perceber diferentes visões acerca do trabalho. Uma delas é a de que o trabalho se constituiu como uma experiência positiva na vida do jovem, como segue o depoimento:

Era 4 horas só, menos até, era muito pouco tempo, então o tempo que ele ficava, ele ficava mexendo com a terra. O V. é muito simpático, muito falante, então ele cativa qualquer pessoa. Mas quando ele foi trabalhar foi legal sim, ele gostou. P5 - Mãe.

Existem participantes que incentivaram o jovem ir para o trabalho, vendo bons resultados neste processo. A família reconheceu o desenvolvimento e as mudanças que ocorreram com o jovem quando ele foi trabalhar.

\begin{abstract}
Olha, pelos irmãos dele e por mim, eu achei que foi um desenvolvimento bastante grande assim sabe, porque ele mudou completamente, não sei, sabe aquela rotina... ficava o dia inteiro, sem fazer nada... Agora com o trabalho ele ta assim bem desenvolvido, que de primeiro quando ele não fazia nada, ele ficava muito agitado, ele andou passando pela neurologista, ela passava um calmante pra ele acalmar um pouco, você entende? Só que agora não precisa ele tomar mais, não sei se é o cansaço. P10-Mãe.
\end{abstract}

Em outro caso, a mãe acreditou no potencial do filho e na capacidade do jovem para o trabalho. Houve um estímulo para que ele fosse trabalhar e hoje a mãe se orgulha em vê-lo realizando diferentes funções:

Essa é primeira vez trabalhando registrado, agora dia 3 vai fazer um ano que ele ta lá na lanchonete. Então, antes eles [a instituição] puseram ele no postinho de saúde, pra ver se ele se saia no meio do público assim, sabe? Porque era só eu, a escola e eu, a escola e eu. Ai viram que ele tem capacidade de ficar longe de mim, de fazer as coisinhas. P10-Mãe.

Existem alguns tipos de trabalho que são ideais na visão da família e outros que não se enquadram para o jovem. Cabe lembrar que quando surge alguma oportunidade de 
trabalho para o jovem através da instituição, a família é que vai decidir se aquele tipo de trabalho é o melhor para o seu filho. A família tem essa possibilidade de escolha do emprego para o jovem, não aceitando necessariamente a primeira opção que the é oferecida pela instituição.

Para Pueschel (2009), é muito comum que indivíduos com SD sejam estereotipados no plano vocacional e por isso, são encaminhados para posições de pouco reconhecimento. Embora estas ocupações possam ser complexas e pessoalmente gratificantes para muitos indivíduos, muitas vezes representam uma falta de consideração pelos interesses e aptidões do trabalhador.

Ainda hoje a maior parte do trabalho oferecido à pessoa com SD é aquele repetitivo (LIMA; SILVA; GALVÃO, 2010).

Outras vezes a empresa não está disposta a treinar uma equipe para ter uma pessoa com deficiência no seu quadro de funcionários, então, coloca o jovem para desenvolver função mais simples, que exige menos, mesmo este tendo capacidade de realizar mais.

Frequentemente quem faz a escolha se o jovem vai ou não para o trabalho são os pais. Segundo Saad (2003), a pessoa com SD, por seu saber considerado ingênuo e desqualificado, não é ouvida a respeito de suas preferências e interesses e isto inibe o desenvolvimento de sua autonomia.

Nem sempre o trabalho traz uma experiência de sucesso, em alguns casos, essa vivência pode ser vista como uma experiência negativa, causando frustrações para a família e principalmente para o jovem.

Então acho que é uma coisa que ele ficou muito chateado porque... coisa de um mês, um mês e pouco, antes deles mandarem embora, todo dia que ia buscar eles me chamavam pra subir, era uma reclamação que tinha, e essa reclamação era feita perto dele, entendeu? Nunca longe... então foi uma coisa assim muito estressante, tanto pra mim quanto pra ele. E de lá pra cá não trabalhou mais, eu acho que ele não ta preparado, não é o momento ainda. P7 - Mãe.

A experiência, tanto de estágio como de trabalho, pode ser bemsucedida, mas, muitas vezes acaba sendo interrompida por outros fatores. Um dos participantes aponta a questão de saúde, que na visão dela, atrapalha o desenvolvimento do jovem no trabalho. Além disso, existe a questão do cuidado. Para os pais, por mais que seja um jovem, ele ainda precisa de cuidado de alguém que esteja sempre próximo, que se responsabilize, para que se sintam seguros em deixar os filhos irem trabalhar. Neste contexto, cabe lembrar que existe 0 despreparo ou pouco preparo dos locais de trabalho, bem como dos empregadores que irão 
receber a pessoa com deficiência. Tudo isso acaba afetando a confiança dos pais em deixar o filho trabalhar.

É importante que o jovem tenha experiência de trabalho, pois em algum momento a instituição não irá mais suprir suas necessidades e demandas, como destaca um dos participantes:

Ele fez uma entrevista, tem 20 dias eu acho... Só que ele foi super contente, ele foi disposto [...] quer trabalhar. Sabe, a impressão que a gente tem aqui [instituição], é que aqui já deu o que tinha que dar pra ele, ele busca outras coisas diferentes, que a gente percebe que ele ta buscando alguma coisa da idade dele. P11-Mãe.

Um estudo específico sobre a melhoria da qualidade de vida das pessoas com SD (MCKINSEY \& COMPANY, 2014), constatou que a inclusão da pessoa com deficiência intelectual costuma ser a de maior complexidade. Em geral, as empresas não estão preparadas para receber funcionários com restrições relacionadas ao raciocínio lógico, memória e comunicação. Isso exige maior dedicação no treinamento e acompanhamento desses profissionais quando comparado às outras deficiências.

O estudo também aponta que ao trabalhar, as pessoas com SD tem a chance de ter sua qualidade de vida potencializada devido às novas relações sociais, aprendizados técnicos e desenvolvimento de autonomia. Durante a vida adulta é o trabalho que vai proporcionar a pessoa com SD o sentimento de pertencimento, de inclusão social. Segundo o estudo, o ambiente de trabalho acelera o desenvolvimento, proporcionando um aprendizado que não pode ser adquirido em outros ambientes.

As pessoas com SD enfrentam muitas adversidades ao longo da vida, incluindo questões relacionadas à saúde, à aprendizagem escolar, aos preconceitos e à inclusão profissional. Um dos maiores obstáculos enfrentados no processo de inclusão referem-se à negação da identidade adulta das pessoas com SD, por parte tanto da família como dos profissionais que atendem (GLAT, 1989 apud MACHADO; CHIARI, 2009).

\section{Trabalho X BPC}

Quando adentramos na temática do trabalho e do BPC, a maioria dos participantes diz não abrir mão do benefício recebido pelo filho em favor da inserção dele no trabalho. São várias as razões para tal. A primeira delas refere-se a ser o BPC utilizado com os gastos domésticos, ajudando na manutenção da casa. 
Olha, eu não abro mão do benefício não, porque é o nosso, é a nossa ajuda, porque além de tudo, que a gente vive disso basicamente [...] então eu não abro mão do benefício dela não, não abro porque eu sei que é muito importante pra gente esse benefício. E pra tudo, pra tudo. P1 - Mãe.

No caso deste participante, o BPC é a única fonte de renda da família sendo, portanto, essencial. Não só essa, mas muitas famílias temem perder este benefício, pois o veem como essencial.

Outra razão refere-se ao receio dos participantes da forma com que o jovem, ao inserir-se no mercado de trabalho, será recebido, se este será aceito, acolhido, e se realmente está preparado para vivenciar esta experiência.

\footnotetext{
Sinceramente eu não trocaria por causa dele ir pra um trabalho, que eu não sei como ele vai ser recebido...As atitudes dele, uma por causa da visão dele, que eu tenho muito medo que alguma coisa pode acontecer, ele pode perder a visão, e assim... Em casa, ele fica em casa sim, mas ele tem as atividades dele, de exercício, de sociabilidade com outras pessoas, e a escola também. P5-Mãe.
}

Como pode ser lido na fala anterior, o problema de saúde se soma como mais uma das razões para a não inserção do jovem no mercado de trabalho e para a manutenção do benefício.

Outra razão diz respeito à pouca disponibilidade de familiares para acompanhar o jovem ao trabalho. Alguns participantes relataram não ter saúde e disposição para acompanhar a rotina do jovem no trabalho, a qual exige muito mais do que disponibilidade e tempo. Inserir o jovem no trabalho não está apenas relacionado ao levar e buscar por exemplo. Requer paciência, vontade, disponibilidade, pois qualquer contratempo que venha a ocorrer no trabalho, os pais serão acionados. Dessa forma, torna-se mais cômodo para a família o jovem permanecer em casa.

Olha, por um momento que eu to passando dificuldade, não to bem de saúde pra ta conduzindo ela até o serviço e buscando, por motivo que eu não deixo ela ir sozinha, a preocupação é muito grande, isso faz com que, às vezes, eu fico preocupada de um momento eu não poder ta conseguindo fazer isso ai. As vezes penso até de faltar aqui nesse mundo e não ter assim ninguém pra que faça o que eu faço com R.... P4 - Mãe

Outros participantes dizem claramente que não tem condições de acompanhar o jovem e desistiram de inseri-los no mercado de trabalho.

Ainda, outro motivo revelado por um participante é a de não acreditar no potencial do jovem com SD, rotulando-o de preguiçoso. 
Não, se fosse pra ele trabalhar assim, eu não fazia questão do benefício porque dava pra gente cuidar dele, mas agora ele cismou que ele não vai trabalhar [...] porque assim mesmo na academia você precisa ver, ele tem uma preguiça, ele vai na academia o dia que ele quer... Então eu acredito que para o trabalho ele vai fazer a mesma coisa, o dia que ele não tiver bem, ele não vai querer ir. P3 - Avó

Como se pode verificar há sempre mais de uma razão nas justificativas para a não inserção dos jovens em empregos: são as limitações do cuidador para levar e buscar o jovem ao trabalho, é o jovem que não deseja se vincular ao trabalho, é a visão da família de que ele não tem perfil para o trabalho, dentre outros. No entanto, pode-se considerar que subjaz a essas razões, a segurança que o BPC oferece do rendimento econômico mensal.

Existem aqueles jovens que optaram pelo trabalho em vez de continuar recebendo o BPC. Os participantes relatam apoio a decisão do jovem, notam que o trabalho trouxe grandes mudanças, reconhecem os seus benefícios.

\begin{abstract}
Olha, eu num tenho escolha porque o benefício é um salário mínimo, ele ta recebendo um salário mínimo, quer dizer que fica elas por elas. Mas o que ele está ganhando com o trabalho? Ah sim, com o trabalho, é melhor por que ele tem desenvolvimento com o público, você entende? Ele não fica estressadinho, você entende? E com o benefício não, é uma coisa assim que ele ta recebendo aquele benefício, mas ele ta ali parado, dentro de casa, sem fazer nada, uma hora dá um tédio daquele né? Então quer dizer que pra mim, na minha opinião, eu acho que com o trabalho teve uma evolução bastante, fez muito bem pra ele... agora o ganhar mais e o ganhar menos é a mesma coisa. P10-Mãe
\end{abstract}

De acordo com esta fala, o benefício e o salário recebido com o trabalho podem ter o mesmo valor monetário, mas o trabalho modifica a vida do jovem, tornando mais reconhecido e isso faz uma grande diferença na vida das famílias. Com o trabalho dificilmente o jovem ficará isolado, pois o trabalho cria uma rotina, preenche a vida, faz com que ele se sinta valorizado. Se o jovem não possui atividades que realiza fora do ambiente doméstico, consequentemente não terá relacionamentos externos à família, e poderá desenvolver algumas doenças, tais como depressão, obesidade, ansiedade excessiva.

Para Toledo e Blascovi-Assis (2007), embora o trabalho seja apenas uma das possibilidades de inclusão social, o contato direto com o público torna-se de grande importância, já que conviver em sociedade, interagindo com diferentes pessoas e em diferentes meios é um passo para que a sociedade conheça e reconheça a existência dessa população e possa refletir sobre as suas necessidades.

Mas, nem sempre é fácil para a família tomar a decisão de permitir ao jovem ir para o trabalho e abrir mão do benefício. 
Segundo Pueschel (2009), alguns indivíduos com SD podem estabelecer objetivos para si mesmos que podem não ser realizados. Em algumas ocasiões, os pais também demonstram expectativas inapropriadas para o filho. Às vezes, os pais consideram degradante para seu filho um emprego não qualificado ou que paga pouco. Como resultado, podem priválo de uma importante experiência de trabalho e da oportunidade dele se desenvolver.

Em algumas situações, no entanto, a opinião do jovem é levada em consideração.

Fiquei com medo, que eu falei, vai que ela não se adapta no trabalho, não dá certo, depois pra poder conseguir o benefício de novo, não sei como ia ser, se eu ia conseguir ou não, então foi meio complicado. Mas, a vontade dela trabalhar foi maior e a gente apoiou. Olha, eu vejo assim, o benefício ajuda muito, ajuda muito, mas, o trabalho é mais gratificante pra eles, é bem mais gratificante, eles se sentem mais realizados. P6 - Mãe

Para aqueles que não se adaptam ao trabalho, existe a possibilidade de retorno ao BPC, de acordo com a LOAS - Lei $n=8.742 / 93$, alterada pela Lei $n=12.470 / 11$. Se a pessoa com deficiência beneficiária do BPC exercer atividade remunerada, o pagamento de seu benefício será suspenso (e não cessado), podendo ser reativado depois de extinta a relação trabalhista ou a atividade empreendedora ou após o prazo de pagamento do seguro desemprego, sem ter que passar por novo processo de requisição e avaliação do INSS.

Porém, pode-se pensar que nem todos os beneficiários têm essa informação, ou ainda, mesmo informados, temem não conseguir reativar o benefício, e então, preferem não arriscar.

Existem situações em que a família não quer perder a estabilidade do benefício, pois depende dele, ou já passaram por experiências frustrantes do jovem no trabalho. Dessa forma, consideram um risco grande deixar o benefício e pelo trabalho.

Cabe ressaltar que o BPC é um benefício da previdência social não vitalício, que deve ser revisto a cada 2 anos. Dependendo da renda per capita da família, a pessoa com deficiência irá continuar ou não recebendo. Por isso, algumas famílias temem perder este benefício a qualquer momento e acabam apostando no trabalho, também como uma forma de garantir a renda.

Não, não, se ele prefere trabalhar ele vai trabalhar, na boa. É prioridade o trabalho? Ah, com certeza. Que o benefício qualquer hora corta, né? P11 - Mãe

Há famílias que optam por um estágio, onde o jovem fica na condição de aprendiz, geralmente com carga horária reduzida, e, nesta situação, o benefício não é cortado. Este pode ser um dos motivos de a família não optar pelo registro, pois quando isto acontece, o 
benefício é cortado automaticamente. Existe a questão da instabilidade, do medo em não conseguir voltar a receber o benefício depois, caso o jovem seja demitido ou não se adapte ao trabalho.

Esse (benefício) eu nunca contei com ele, sempre foi pra casa, porque eu vou falar pra senhora que eu guardava, não, eu to mentindo [...] então eu nunca tinha guardado um centavo com o benefício dela, então foi assim uma época muito difícil pra mim, então eu tinha que gastar o benefício dela. P4 - Mãe

Cabe lembrar que alguns jovens recebem o benefício há 10 anos ou mais, o que mostra que o benefício já está incorporado à vida econômica da família, a qual passa a contar com ele como uma renda garantida no final do mês.

A Constituição de 1988 estabeleceu o BPC para pessoa com deficiência e não para a pessoa incapaz, termos que não são sinônimos e não deveriam ser associados para qualquer fim, sob pena de se estimular a não preparação dos jovens com deficiência para a vida em sociedade. É o que está acontecendo na prática. Muitos pais acabam impedindo seus filhos com deficiência de se capacitarem, justamente para não perderem o direito ao benefício (SANTOS, 2011).

Pueschel (2009) explica que por meio do trabalho as pessoas com SD adquirem um sentido de valor próprio de que estão contribuindo para a sociedade. A experiência profissional é importante para todas as pessoas, mas particularmente para as pessoas com deficiência, já que representa uma chance para eles provarem que são capazes. Uma realização desse tipo aumenta sua autoestima e satisfará sua família, além da sociedade também reconhecer sua contribuição.

\section{Considerações Finais}

Os participantes da pesquisa revelaram diferentes percepções em relação aotrabalho do jovem com SD e ao BPC e, consequentemente, as diferentes motivações para a escolha de um ou outro.

Os jovens que recebem o benefício são vistos pela família como uma pessoa com limitações, dependentes e com dificuldades de inserção social. Dessa forma, a possibilidade de colocação do jovem no mercado de trabalho é remota. A necessidade de acompanhar o jovem no trajeto de ida e volta ao trabalho por um membro da família, os problemas de saúde de pais ou responsáveis dos jovens são outras razões que corroboram a decisão de que o melhor para o jovem é ficar em casa. 
Este estudo também mostrou que o BPC é visto por algumas famílias como algo fundamental na economia doméstica, pois sem ele encontram dificuldades financeiras para suprir seus gastos básicos. Assim, excluir o jovem do mercado de trabalho e manter o BPC pode ser configurado, em alguns casos, como estratégia de sobrevivência para a família.

As experiências positivas daqueles que trabalham foram referidas pela família como autonomia e independência.

Pode-se constatar que coube à família (pais ou responsáveis) do jovem escolher entre o trabalho e o BPC, e para tanto, consideraram ganhos e perdas, vantagens e desvantagens. A falta de informações ou o descrédito em relação à possibilidade de voltar a receber o BPC nos casos de não adaptação ao trabalho por parte dos jovens influenciaram na decisão de não encaminhá-los ao mercado de trabalho. A desconfiança em relação à capacidade da empresa em bem alocar o jovem também foi mencionada.

O BPC configura-se, em importante mecanismo de proteção social às famílias em situação de vulnerabilidade, em especial às famílias dos jovens com Síndrome de down, que dependem deste benefício para sua sobrevivência. No entanto, pela percepção da segurança financeira que ele oferece às famílias, pode ser também desestímulo ao ingresso do jovem com SD no mercado de trabalho.

A necessidade de orientação às famílias dos jovens com SD quer seja em relação às regras e condições do benefício assistencial, quer seja em relação às possibilidades de trabalho para o jovem, são prementes.

\section{Referências}

AMARAL, L. Mercado de trabalho e deficiência. Revista Brasileira de Educação Especial, Marília, v. 1, n. 2, p. 127-136, 1994.

BAMPI, L.N.S.; GUILHEM, D.; ALVES, E.D. Modelo social: uma nova abordagem para o tema deficiência. Revista Latino-Americana de Enfermagem, Ribeirão Preto, v. 18, n. 4, p. 816-823, jul./ago. 2010.

BARDIN, L. Análise de conteúdo. Lisboa: Edições 70, 2006.

BRASIL. Lei 8.742, de 7 de dezembro de 1993. Dispõe sobre a organização da assistência social e dá outras providências. Disponível em: <http://www.planalto.gov.br/ccivil_03/leis/ 18742.htm>. Acesso em: 20 fev. 2017.

BRASIL. Ministério do Desenvolvimento Social. Beneficiários do BPC têm até 2018 para fazer inscrição no Cadastro Único. 2017. Disponível em: <http://mds.gov.br/area-de- 
imprensa/noticias/2017/dezembro/beneficiarios-do-bpc-tem-ate-2018-para-fazer-inscricaono-cadastro-unico>. Acesso em: $20 \mathrm{dez} .2017$.

BRASIL. Lei no 8.213, de 24 de julho de 1991. Dispõe sobre os Planos de Benefícios da Previdência Social e dá outras providências. Disponível em:

<http://www.planalto.gov.br/ccivil_03/leis/L8213cons.htm>. Acesso em: 20 dez. 2017.

COLMAN, E.; POLA, K. Trabalho em Marx e Serviço Social. Revista de Serviço Social, Londrina, v. 12, n. 1, p. 179-201, 2009.

COSTA, N. R. et al. Proteção social e pessoa com deficiência no Brasil. Revista Ciência \& Saúde Coletiva, Rio de Janeiro, v. 21, n. 10, p. 3037-3047, out. 2016. Disponível em:<http://www.scielo.br/scielo.php?script=sci_arttext\&pid=S1413-

81232016001003037\&lng=en\&nrm=iso\&tlng=pt>. Acesso em: 15 fev. 2017.

DEJOURS, C. Addendum: da psicopatologia à psicodinâmica do trabalho. In: LANCMAN, S.; SZNELWAR, L. I. (Org.). Christophe Dejours: da psicopatologia à psicodinâmica do trabalho. Rio de Janeiro: Fiocruz, 2004. p. 277-299.

DINIZ, D.; BARBOSA, L.; SANTOS, W.R. Deficiência. Revista Internacional de Direitos Humanos, São Paulo, v. 6, n.11, p.65-77, 2009.

EDWARDS, J. Adolescência e vida adulta. In: PUESCHEL, S. (Ed.). Síndrome de Down: guia para pais e educadores. Campinas: Papirus, 2009. p. 267-76.

GIORDANO, B. Deficiência e trabalho: analisando suas representações. São Paulo: Editora Annamblume/FAPESP, 2000.

KASSAR, M.C.M. Conhecimento: direito ao conhecimento e modos de conhecer: novas condições. In: CONFERÊNCIA DE PESQUISA SOCIOCULTURAL, 3., 2000, Campinas, 2000. Anais... Campinas, 2000. Disponível em:<www.fae.unicamp.br/br2000/conh9.htm>. Acesso em: 15 mar. 2016.

LIMA, M.P.; TAVARES, N.V.; BRITO, M. J. O sentido do trabalho para pessoas com deficiência. Revista de Administração Mackenzie, São Paulo, v. 14, n. 2, p. 42-68, 2013.

LIMA, J.; SILVA, T.D.; GALVÃO, E. A percepção dos empregadores sobre a admissão de trabalhadores com Síndrome de Down. Health Scientist Institute, Bethesda, v. 28, n. 1, p. 1720, 2010.

LEPRI, C. Viajantes inesperados: notas sobre a inclusão social das pessoas com deficiência. Campinas: Saberes, 2012.

MACHADO, M.; CHIARI, B. Estudo das habilidades adaptativas desenvolvidas por jovens com Síndrome de Down incluídos e não incluídos no Mercado de trabalho. Saúde e Sociedade, São Paulo, v. 18, n. 4, p. 652-61, 2009.

MARTINELLI, M.L. O serviço social e a consolidação de direitos: desafios contemporâneos. Revista Serviço Social \& Saúde, Campinas, v. 10, n. 12, p. 1-17, 2011. 
MCKINSEY \& COMPANY. Os valores que os colaboradores com síndrome de down podem agregar as organizações. 2014. Disponível em:

<http://www.pessoacomdeficiencia.sp.gov.br/content/uploads/201432419413Estudo INSTITUTO ALANA>. Acesso em: 22 jun. 2016.

MINAYO, M. O desafio do conhecimento: pesquisa qualitativa em saúde. 8. ed. Rio de Janeiro: Abrasco, 2004.

NETTO, J. P. FHC e a política social: um desastre para as massas trabalhadoras. In:

LESBAUPIN, I. (Org.). O desmonte da nação: balanço do governo FHC. 2. ed. Petrópolis: Vozes, 1999. p. 75-89.

PEREIRA, P.A. Política de assistência social no Brasil: avanços e retrocessos. Caderno do CEAM, Brasília, v. 3, n. 11, p. 63-80, 2002.

PUESCHEL, S. Síndrome de Down: Guia para pais e educadores. 13. ed. Campinas: Papirus, 2009.

RAIÇA, D.; PRIOSTE, C.; MACHADO, M. L. G. Dez questões sobre a educação inclusiva da pessoa com deficiência mental. São Paulo: Avercamp, 2006.

RAUET, J. Síndrome de Down de A a Z: um guia para pais e profissionais. Campinas: Saberes, 2011.

SAAD, S. Preparando o caminho da inclusão: dissolvendo mitos e preconceitos em relação à pessoa com síndrome de down. Revista Brasileira de Educação Especial, Marilia, v. 9, n. 1, p. 57-78, 2003.

SANTOS, W. Deficiência e BPC: o que muda na vida das pessoas atendidas? Ciência e Saúde Coletiva, Rio de Janeiro, v. 16, n. 1, p. 787-96, 2011.

SASSAKI, R. Inclusão: construindo uma sociedade para todos. Rio de Janeiro: WVA, 1997.

SENNA, M.C.M.; LOBATO, L.V.C. Proteção social à pessoa com deficiência no Brasil Pós Constituinte. Ser Social, Brasília, v. 15, n. 32, p. 11-33, 2013.

TOLEDO, A.; BLASCOVI-ASSIS, S. Trabalho e deficiência: significado da inclusão no mercado formal para um grupo de jovens com síndrome de down. Caderno de Pós- graduação em Distúrbios do Desenvolvimento, v. 7, v. 1, p. 83-96, 2007. 